\title{
Opioid-Prescribing Continuity and Risky Opioid Prescriptions
}

Sara E. Hallvik, $M P H^{1}$

Peter Geissert, $M P H^{2}$

Wayne Wakeland, $P b D^{2}$

Christi Hildebran, LMSW'

Jody Carson, RN, MSW'

Nicole O'Kane, PharmD ${ }^{1}$

Richard A. Deyo, MD, MPH

'HealthInsight Oregon, Portland, Oregon

${ }^{2}$ Portland State University, Portland,

Oregon

${ }^{3}$ Department of Family Medicine, Department of Medicine, and The Oregon Institute for Occupational Health Sciences, Oregon Health and Science University, Portland, Oregon
Conflicts of interest: Richard A. Deyo receives royalties from UpToDate for authoring topics on low back pain and previously received bonoraria for board membership at the nonprofit Informed Medical Decisions Foundation. His salary at Oregon Health \& Science University is supported in part by an endowment from Kaiser Permanente. He received a financial award from NuVasive as part of a lifetime achievement award from the International Society for Study of the Lumbar Spine. All other authors report none.

\section{CORRESPONDING AUTHOR}

Sara E. Hallvik, MPH

HealthInsight Oregon

2020 SW 4th Ave, Suite 520

Portland, OR 97201

shallvik@healthinsight.org

\begin{abstract}
We aimed to better understand the association between opioid-prescribing continuity, risky prescribing patterns, and overdose risk. For this retrospective cohort study, we included patients with long-term opioid use, pulling data from Oregon's Prescription Drug Monitoring Program (PDMP), vital records, and hospital discharge registry. A continuity of care index (COCl) score was calculated for each patient, and we defined metrics to describe risky prescribing and overdose. As prescribing continuity increased, likelihood of filling risky opioid prescriptions and overdose hospitalization decreased. Prescribing continuity is an important factor associated with opioid harms and can be calculated using administrative pharmacy data.
\end{abstract}

Ann Fam Med 2018;16:440-442. https://doi.org/10.1370/afm.2285.

\section{INTRODUCTION}

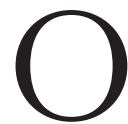
pioid prescribing has increased substantially from 1999 through 2011, with accompanying increases in overdoses, deaths, and addiction therapy. ${ }^{1}$ In an effort to reduce risks, clinical guidelines, clinic policies, and medication contracts often emphasize continuity of opioid prescribers. Little is known, however, about how prescriber continuity influences risky prescribing patterns or overdose risk, or how the continuity of opioid prescribing compares with other long-term medications.

We used the Oregon Prescription Drug Monitoring Program (PDMP) data to (1) examine the association between continuity of long-term opioid prescribing and both prescribing patterns and patient outcomes, and (2) to compare prescribing continuity among patients with long-term opioid, benzodiazepine, or stimulant use.

\section{METHODS}

Prescription data were obtained from the Oregon PDMP. Data on opioidrelated deaths were found in the Oregon vital records, and data on opioidrelated hospitalizations were found in a statewide hospital discharge registry. Preparation of the data set is described elsewhere. ${ }^{2,3}$

For each patient who filled 1 or more opioid, schedule II stimulant, or benzodiazepine prescription between October 1, 2011, and September 30, 2014, we tabulated the number of prescriptions filled for each drug category in each 6 -month interval. We considered patients who filled 3 or more prescriptions of a single drug category in every 6 -month period to be long-term users of that drug category. Patients younger than 18 years were excluded. The 3 drug category cohorts are not mutually exclusive, so a single patient could be included in more than 1 category.

To calculate the continuity of prescribing index, we identified a primary prescriber for each patient in each 6 -month period. This prescriber wrote the most categorical prescriptions (eg, opioids) for each patient. We then measured the continuity of care index $(\mathrm{COCI}){ }^{4}$ This index accounts for the total number of prescribers across 6 -month periods in addition to the 
proportion of 6-month periods in which a single prescriber was identified as the primary prescriber. Patients with long-term opioid use were divided into quartiles of COCI to examine the likelihood of filling risky prescriptions or experiencing opioid-related harms.

Measures of high-risk opioid prescribing were calculated for each patient in each of the 6-month periods. Inappropriate opioid prescription referred to a prescription written for the same opioid within 7 days after a prescription of at least 30 tablets from a different prescriber. ${ }^{5}$ All other metrics are defined in the most recent Centers for Disease Control and Prevention prescribing guidelines. ${ }^{6}$ Inappropriate opioid prescriptions and multiple prescriber metrics are inherently correlated with $\mathrm{COCI}$, as both are measures of multiple prescribers.

Opioid-related hospitalizations and deaths were identified using the International Classification of Diseases, Ninth Revision, Clinical Modification (ICD-9-CM) and the

\section{Table 1. Demographic Distribution of Patients With Long-Term Use of Stimulants, Opioids, or Benzodiazepines}

\begin{tabular}{llcc}
\hline $\begin{array}{l}\text { Character- } \\
\text { istic }\end{array}$ & $\begin{array}{c}\text { Stimulants } \\
\text { No. (\%) }\end{array}$ & $\begin{array}{c}\text { Opioids } \\
\text { No. (\%) }\end{array}$ & $\begin{array}{c}\text { Benzodiazepines } \\
\text { No. (\%) }\end{array}$ \\
\hline $\begin{array}{l}\text { Total No. } \\
\text { Age, y }\end{array}$ & 9,014 & 78,056 & 31,437 \\
$18-44$ & $4,648(51.6)$ & $13,850(17.7)$ & $5,972(19.0)$ \\
$45-54$ & $1,888(21.0)$ & $17,724(22.7)$ & $7,257(23.1)$ \\
$55-64$ & $1,807(20.1)$ & $24,371(31.2)$ & $9,858(31.4)$ \\
$\geq 65$ & $671(7.4)$ & $22,111(28.3)$ & $8,350(26.6)$ \\
Location & & & \\
$\quad$ Urban & $6,541(72.6)$ & $43,696(56.0)$ & $18,547(59.0)$ \\
Rural & $2,317(25.7)$ & $32,949(42.2)$ & $12,454(39.6)$ \\
\hline $\begin{array}{l}\text { a Excludes 1,411 (1.8\%) non-Oregon and unknown patients with long-term use } \\
\text { of opioids, 156 (1.7\%) stimulants, and 436 (1.4\%) benzodiazepines. }\end{array}$ \\
\hline
\end{tabular}

International Classification of Diseases, Tenth Revision, Clinical Modification (ICD-10-CM) diagnosis codes, as described elsewhere. ${ }^{2}$ Heroin-related deaths were included, as heroin use may sometimes be a consequence of prescription opioid use. ${ }^{7}$

We tabulated the number and percentage of patients with long-term opioid use who received highrisk prescriptions, were hospitalized for opioid-related causes, or died of an opioid overdose within each quartile of $\mathrm{COCI}$ score. Cochran-Armitage tests for trend were used to examine differences in the proportions of patients in each incremental quartile who received risky prescriptions or experienced adverse events. We calculated pairwise $t$ tests to compare COCI scores between drug categories. Analysis was conducted using SAS 9.4 (SAS Institute, Inc); statistical significance was set at $P=.05$.

Activities were approved by 2 institutional review boards: Oregon Health \& Science University and the Public Health Division of the Oregon Health Authority, where the PDMP is located.

\section{RESULTS}

During the study period, 1,701,352 patients filled an opioid prescription, 78,056 (4.6\%) of whom were included as patients with long-term opioid use. There were 119,529 patients who filled a stimulant prescription, and 9,014 (7.5\%) were included as having longterm use. Finally, 596,978 patients filled a prescription for a benzodiazepine, and 31,437 (5.3\%) were included as patients with long-term use. Patient characteristics are displayed in Table 1.

Patients with greater opioid-prescribing continuity received fewer risky prescriptions than patients in the lowest continuity quartile, and they were less likely to be hospitalized for opioid-related causes (Table 2).

Table 2. Long-Term Opioid-Use Patients With Risky Opioid Prescriptions or Opioid Harms in Each Continuity of Care Index Quartile

\begin{tabular}{lcccccc}
\hline & & \multicolumn{5}{c}{ Continuity of Care Index } \\
Characteristic & Total & Quartile 1 & Quartile 2 & Quartile 3 & Quartile 4 & Value \\
\cline { 3 - 6 } Quartile index score, range & $0.005-1.00$ & $0.005-0.411$ & $0.412-0.639$ & $0.640-0.855$ & $0.856-1.000$ \\
Number of patients & 78,056 & 19,510 & 19,518 & 19,471 & 19,557 & \\
High-dose opioid, No. (\%) & $29,063(37.2)$ & $7,944(40.7)$ & $7,194(36.9)$ & $6,958(35.7)$ & $6,967(35.6)$ & $<.0001$ \\
Opioid-benzodiazepine overlap, No. (\%) & $43,884(56.2)$ & $12,364(63.4)$ & $11,154(57.2)$ & $10,572(54.3)$ & $9,794(50.1)$ & $<.0001$ \\
Long-acting opioid, No. (\%) & $36,149(46.6)$ & $10,549(54.1)$ & $9,242(47.4)$ & $8,529(43.8)$ & $7,829(40.0)$ & $<.0001$ \\
Using $\geq 4$ opioid prescribers, No. (\%) & $23,488(30.1)$ & $12,799(65.6)$ & $7,049(36.1)$ & $3,436(17.7)$ & $204(1.0)$ & $<.0001$ \\
Inappropriate opioid prescription, No. (\%) & $19,395(24.9)$ & $8,246(42.3)$ & $5,322(27.3)$ & $4,258(21.9)$ & $1,569(8.0)$ & $<.0001$ \\
Any opioid hospitalization, No. (\%) & $3,034(3.9)$ & $1,122(5.8)$ & $835(4.3)$ & $674(3.5)$ & $403(2.1)$ & $<.0001$ \\
Opioid overdose death, No. (\%) & $22(0.0)$ & $6(0.0)$ & $6(0.0)$ & $6(0.0)$ & $4(0.0)$ & .2828 \\
\hline a Quartiles divided into lowest continuity (Q1) to highest continuity (Q4) index scores. & & & & &
\end{tabular}


Opioid-related deaths were rare and similar among quartiles.

Patients with long-term opioid use had significantly lower average COCI scores (0.74; SD, 0.21) than patients with long-term stimulant use $(0.82 ; \mathrm{SD}$, $0.19)$ or long-term benzodiazepine use $(0.82$; SD, $0.20), P<.0001$.

\section{DISCUSSION}

Lower continuity of prescribing, as measured by COCI, is strongly associated with the likelihood of filling high-risk opioid prescriptions or being hospitalized for an opioid-related cause among patients with long-term opioid use. Patients with long-term opioid use had significantly lower prescriber continuity than patients with long-term benzodiazepine or stimulant use, suggesting that efforts are still needed to improve opioid-prescribing continuity.

By directly connecting a prescriber continuity index to risky prescriptions and opioid-related hospitalizations, these results build upon other findings associating long-term opioid use with a larger number of prescribers ${ }^{8}$ and adverse outcomes. ${ }^{9,10}$

Our data support the clinical importance of continuity in opioid prescribing but suggest that further efforts may be necessary to optimize this continuity. This study also suggests that prescribing continuity can be calculated from pharmacy data using validated continuity of care indices. This application is novel, raising the possibility of measuring prescriber continuity in the absence of medical visit data.

This study has important limitations. Patient diagnosis was not available in our data sets, so we could not determine the conditions for which medications were prescribed. Patients with complicated medical conditions and more prescribers could have lowered COCI calculations, but by identifying a primary prescriber in each 6-month period, we mitigated this concern by containing the impact within each period.

Using continuity of care indices to measure prescriber continuity warrants further study. Calculating continuity of prescribing indices using different time scales (eg, continuous, monthly, or quarterly) may capture different aspects of prescribing continuity. Such indices may be valuable predictors in models of overdose risk.

Understanding the factors that increase the risk of opioid-related harms and deploying preventive strategies are essential components of safe pain management.
Prescribing continuity is an important factor associated with opioid harms and can be calculated using administrative pharmacy data.

To read or post commentaries in response to this article, see it online at http://www. AnnFamMed.org/content/16/5/440.

Key words: opioids; pain; prescribing continuity; continuity of care

Submitted December 21, 2017; submitted, revised, May 2, 2018; accepted May 24, 2018.

Funding support: This study was supported by a grant No. R01 DA031208 from the National Institute on Drug Abuse, and by grant No. UL 1RR024140, from the National Center for Advancing Translational Sciences.

Acknowledgments: The authors thank Kevin Novak, MS, HealthInsight Oregon, for his literature review and EndNote expertise; Neidra Evans, BS, HealthInsight Oregon, who provided essential budgetary and administrative support; and David Sobieralski, Healthlnsight Oregon, who provided project assistance with this study.

\section{References}

1. Rudd RA, Aleshire N, Zibbell JE, Gladden RM. Increases in drug and opioid overdose deaths-United States, 2000-2014. MMWR Morb Mortal Wkly Rep. 2016;64(50-51):1378-1382.

2. Deyo RA, Hallvik SE, Hildebran C, et al. Association between initial opioid prescribing patterns and subsequent long-term use among opioid-naïve patients: a statewide retrospective cohort study. J Gen Intern Med. 2017;32(1):21-27.

3. O'Kane N, Hallvik SE, Marino M, et al. Preparing a prescription drug monitoring program data set for research purposes. Pharmacoepidemiol Drug Saf. 2016;25(9):993-997.

4. Pollack CE, Hussey PS, Rudin RS, Fox DS, Lai J, Schneider EC. Measuring care continuity: a comparison of claims-based methods. Med Care. 2016;54(5):e30-e34.

5. Dormuth CR, Miller TA, Huang A, Mamdani MM, Juurlink DN; Canadian Drug Safety and Effectiveness Research Network. Effect of a centralized prescription network on inappropriate prescriptions for opioid analgesics and benzodiazepines. CMAJ. 2012;184(16): E852-E856.

6. Centers for Disease Control and Prevention, National Center for Injury Prevention and Control. CDC guideline for prescribing opioids for chronic pain. Centers for Disease Control and Prevention. https://www.cdc.gov/drugoverdose/prescribing/guideline.html. Published 2016. Updated Aug 29, 2017.

7. Dowell D, Haegerich TM, Chou R. CDC guideline for prescribing opioids for chronic pain-United States, 2016. JAMA. 2016;315(15): 1624-1645.

8. Deyo RA, Smith DH, Johnson ES, et al. Opioids for back pain patients: primary care prescribing patterns and use of services. J Am Board Fam Med. 2011;24(6):717-727.

9. Vowles KE, McEntee ML, Julnes PS, Frohe T, Ney JP, van der Goes DN. Rates of opioid misuse, abuse, and addiction in chronic pain: a systematic review and data synthesis. Pain. 2015;156(4):569-576.

10. Chou R, Turner JA, Devine EB, et al. The effectiveness and risks of long-term opioid therapy for chronic pain: a systematic review for a National Institutes of Health Pathways to Prevention Workshop. Ann Intern Med. 2015;162(4):276-286. 